\title{
Allogeneic LMP1/LMP2-Specific Cytotoxic T-Lymphocytes
}

National Cancer Institute

\section{Source}

National Cancer Institute. Allogeneic LMP1/LMP2-Specific Cytotoxic T-Lymphocytes. NCI Thesaurus. Code C78201.

A preparation of cytotoxic T-lymphocytes (CTL), specifically reactive to the Epstein-Barr virus (EBV) latent membrane proteins (LMP) 1 and 2, with potential antineoplastic activity. Peripheral blood mononuclear cells (PBMC) are collected from a donor and are exposed ex vivo to dendritic cells (DCs) transfected with a replication-deficient adenovirus encoding EBV LMP1/2 to generate LMP1/2-specific CTL which are subsequently expanded. Administration of allogeneic LMP1-/LMP2- specific CT L to patients with LMP1/2-positive tumors may result in a specific CT L response against tumor cells expressing LMP1 and LMP2, resulting in cell lysis and inhibition of tumor cell proliferation. As tumor associated antigens (TAAs), LMP1 and LMP2 are expressed in various malignancies including nasopharyngeal cancer and EBV-positive Hodgkin lymphoma. 